\title{
2,000-year Methane Record in a High Altitude Himalayan Ice Core
}

\author{
$\mathbf{Y}_{\text {ao }}$ Tandong $^{1}, \mathbf{X}_{\mathrm{U}}$ Baiqing $^{1}{ }^{1}$ Jerome Chappellaz ${ }^{2}$ and Lonnie Thompson ${ }^{3}$ \\ ${ }^{1}$ Key Laboratory of Cryosphere and Environment, Institute of Tibetan Plateau Research, CAS, Beijing 100085, China; tdyao@itpcas.ac.cn; \\ baiqing@itpcas.ac.cn \\ 2Laboratoire de Glaciologie et Géophysique de l'Environnement, CNRS, BP96, 38402 Saint Martin d'Hères Cedex, France; \\ chappellaz@lgge.obs.ujf-grenoble.fr \\ 3Byrd Polar Research Center, Ohio State University, Columbus, OH 43210, USA; Thompson.3@osu.edu
}

Ice core methane reconstructions are believed to reflect atmospheric methane concentration fluctuations with time and to reveal past changes in terrestrial methane emissions (Blunier et al., 1993, Chappellaz et al., 1990, 1993). It has been proposed that past natural methane fluctuations were mainly due to changes in source strength, through variability of the wetland extent in tropical regions. Dasuopu ice core, recovered from the Da-

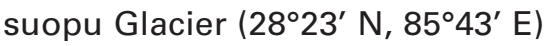
in the center of the Himalayas (Fig. 1), provides a unique opportunity to obtain a sub-tropical latitude methane reconstruction because of its high altitude (7200 m a.s.l), low ice temperatures and limited summer melting.

\section{Measurement and Air Dating}

Two laboratories performed the methane measurements. At the Laboratory of Cryosphere and Environment (LEC), CAS, we used a melt extraction method similar to the one originally developed at LGGE in France. The agreement between the two methane data sets generated by LEC and LGGE was tested at two levels. First, a glass flask filled with the LGGE standard gas was measured at LEC. Second, the Antarctic D47 ice core was cut lengthwise and analyzed several times in both laboratories. The excellent agreement between the LEC and LGGE methane data confirms the validity of the inter-calibration performed between the two laboratories. As the pre-industrial methane trend has already been determined from Greenland (Eurocore, GRIP) and Antarctic (D47) ice cores measured at LGGE using the same technique as for the Dasuopu samples, we are confident that the results presented here can be directly compared to the polar records for determining the difference in the methane mixing ratio

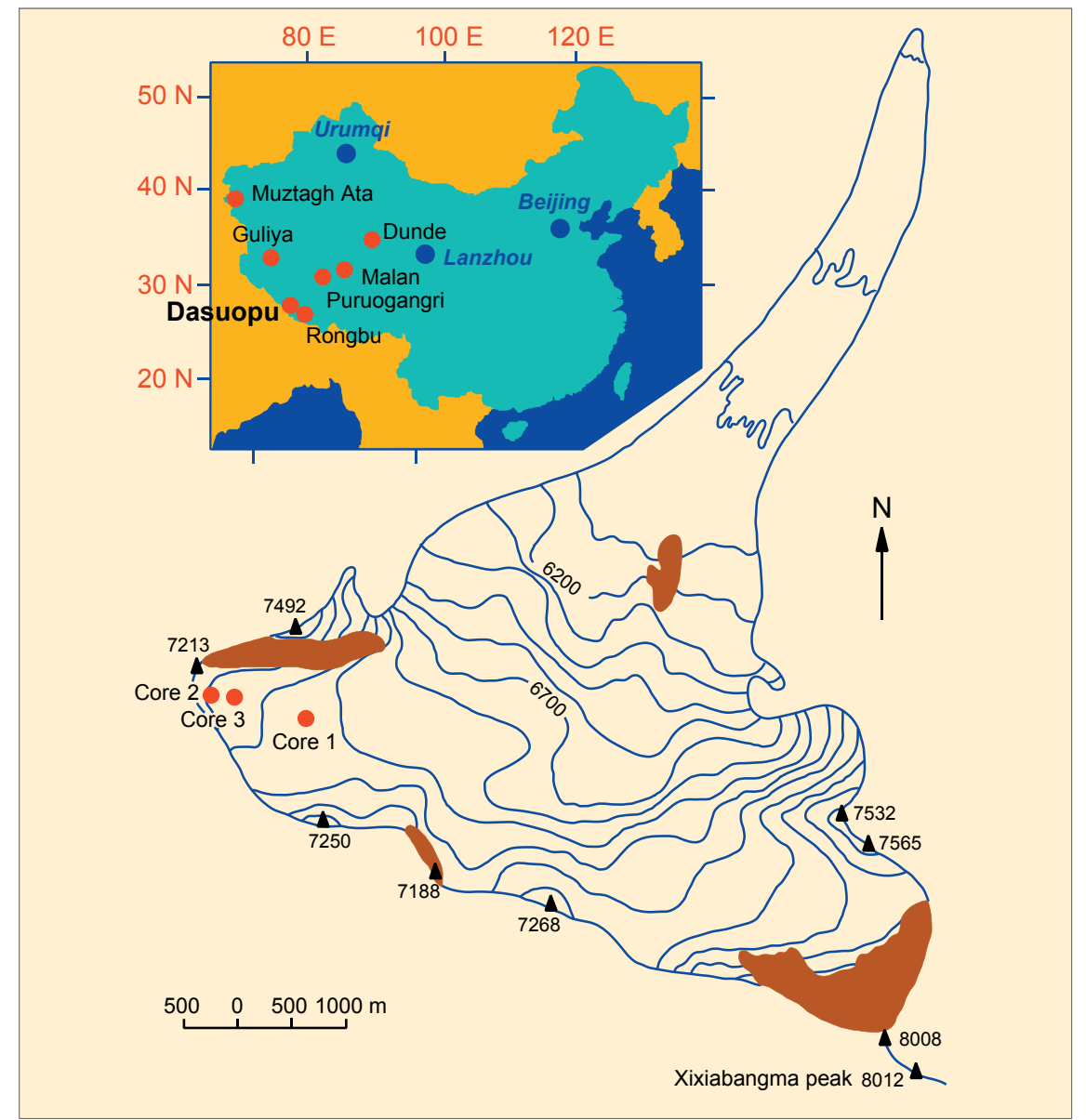

Fig.1: Location of the Dasuopu Glacier relative to the Guliya, Dunde, and Tanggula sites where previous ice cores were recovered. The enlargement of the Dasuopu Glacier shows the ice core sites on the glacier.

between sub-tropical and polar regions.

The upper 550 years to a depth of $122 \mathrm{~m}$ of the Dasuopu ice core were dated using a comprehensive method of counting the seasonal variations in $\delta^{18} \mathrm{O}$, dust and chemical components, such as nitrate. From 122 to $149 \mathrm{~m}$, we determined the timescale by extrapolating the depth-age relation established for the upper $122 \mathrm{~m}$ and by assuming a constant annual accumulation rate.

For the Dasuopu core, ice density, bubble volume and ice structure were all analyzed to determine the specific gas trapping conditions for this site. Our study indicates that pores close off below a depth of about $40 \mathrm{~m}$, and the air forms rapidly into bubbles in the depth interval of 40-47 m. Bubble volume at the firn-ice transition indicates a maximum at a depth of $47 \mathrm{~m}$, which means that half of the bubbles close off at the depth of 45 $\mathrm{m}$. The corresponding ice age at 45 $\mathrm{m}$ is 60 years. Taking into account an estimated 10 years for methane diffusion through the firn column, the age of the trapped methane is approx. 50 years younger than the age of the surrounding ice in the Dasuopu ice core (Xu and Yao, 1999). Estimates of the past accumulation rate on the Dasuopu Glacier come from annual layer thickness measurements and an ice-flow model allowing calculation of the thinning of the ice with depth. This leads to changes in the gas age-ice age dif- 


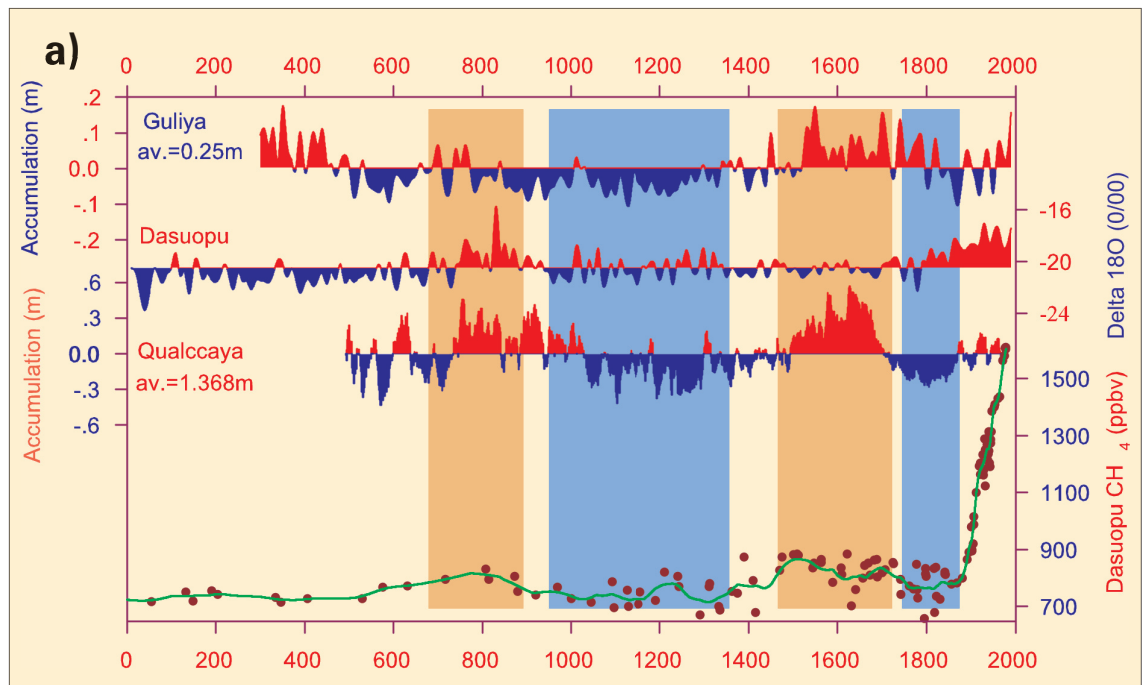

b)

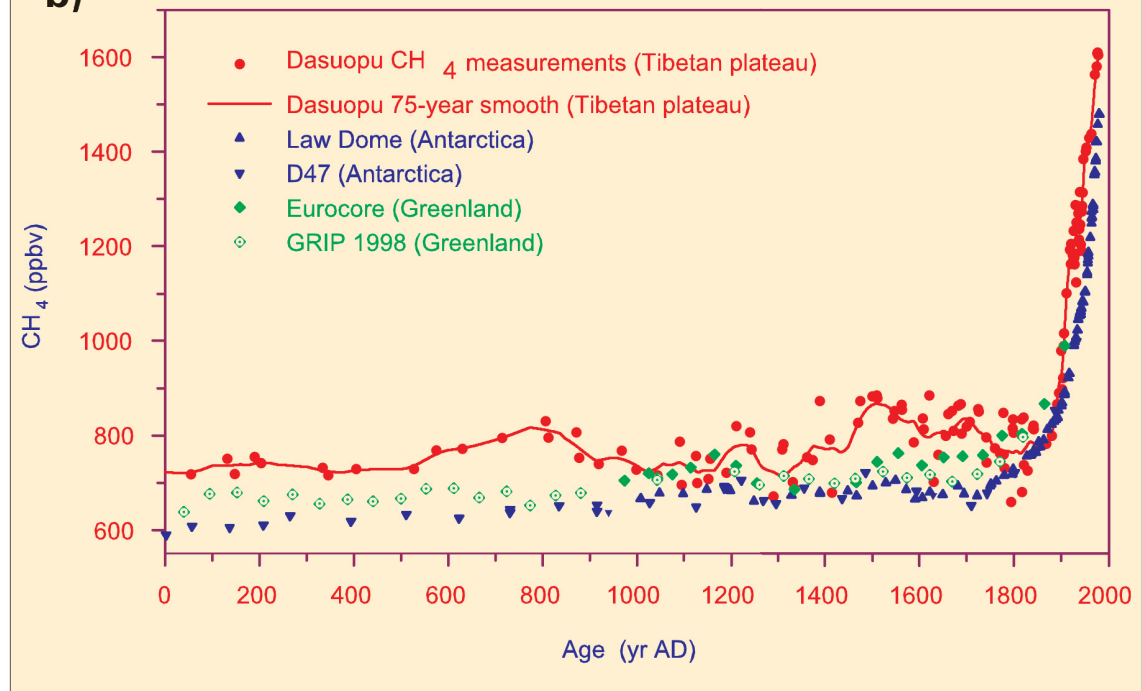

Fig. 2: (a) The Dasuopu methane and $\delta^{18} \mathrm{O}$ record, as well as the accumulations in Guliya and Quelccaya ice cores (Thompson et al., 1985) for the last 2,000 years; (b) A comparison of methane concentration from Dasuopu, Greenland (GRIP and Eurocore) and Antarctica (Law Dome and D47) ice cores.

ference of about $40 \sim 70$ years, which are taken into account in the gas chronology presented here.

\section{Results and Discussion}

Figure 2a shows the Dasuopu methane and $\delta^{18} \mathrm{O}$ record, as well as the accumulations in the Guliya and Quelccaya ice cores for the last 2,000 years. Methane concentration changes coincide with accumulation fluctuations. Guliya, located in the western Tibetan Plateau, and Quelccaya, located in the central Andes, show variations of the methane and $\delta^{18} \mathrm{O}$ records similar to those in the Dasuopu ice core. This suggests that past natural methane fluctuations were mainly due to changes in source strength, through variability of the wetland extent in tropical regions. The last low concentration period in methane appeared around 1800 AD. Although some polar ice cores appear to record a very early (1750 AD) signature of anthropogenic methane, we do not see this in the Dasuopu ice core. In the polar region, the study of Rasmussen and Khalil (1984) concluded that a rapid and significant methane concentration increase started about 150 years ago, which corresponds with our results. They also found that the methane concentration in the atmosphere 250 years before was about $45 \%$ of current values (700 ppbv) and was not significantly influenced by human activities.

Our study concluded that the $\delta^{18} \mathrm{O}$ in the Dasuopu ice core is also a good indicator of temperature (Thompson et al., 2000; Yao et al., 2002). The temperature record over the past 2,000 years, based on the $\delta^{18} \mathrm{O}$ curve in Figure 2a, shows dramatic changes. Early in the first century, temperatures were low, followed by a significant increase until 700 AD. Temperatures reached their maximum during 700 900 AD, then lowered again, on a trend that persisted until 1850 AD. The Dasuopu ice core reconstruction reveals an obvious positive correlation between methane concentration and temperature. For instance, high methane concentrations occurred during the warm period between 700 900 AD. When the Little Ice Age began, around $1500 A D$, there was a corresponding decrease in methane concentration. The methane concentration decrease continued to its lowest level of 660 ppbv during the coldest period indicated by $\delta^{18} \mathrm{O}$ (around 1800 AD). Petit et al. (1999) and Raynaud et al. (1993) conclude that the remarkable correlation between methane and temperature implies a contribution of methane to the glacial-interglacial changes by amplifying the orbital forcing, along with albedo feedbacks and other possible changes. The Dasuopu ice core shows a close positive correlation between methane and $\delta^{18} \mathrm{O}$, even on the very recent timescale.

Comparing the results from the mid-low latitude with that from the polar region reveals some interesting features. The most important feature of the Dasuopu ice core record is that the methane concentration and temporal variation amplitude are greater than in the polar ice core records during the pre-industrial period. The average methane concentration in the Dasuopu record is $782 \mathrm{ppbv}$, and the maximum temporal variation exceeds 200 ppbv, which has not been found in polar ice records for the period from 0-1850 AD. The Antarctic Law Dome cores (Etheridge et al., 1998) combined with the D47 (Blunier et al., 1993) core, the Greenland GRIP core (Blunier et al., 1993), and the Eurocore (Etheridge et al., 1998) provide a very detailed methane reconstruction for the last 2,000 years. Figure $2 b$ shows the gradients of methane concentra- 
tion among the Dasuopu core, the Greenland cores, and the Antarctic cores. The Dasuopu values differ by an average of 66 ppbv from the Greenland values and 109 ppbv from the Antarctic values. The average difference between the Greenland and Antarctic records is 44 ppbv in the time interval of 0-1850 $A D$. The higher methane gradients between the Dasuopu core and the polar region suggest that the lowmiddle latitude acted as the most important methane source in the pre-industrial period.

\section{Conclusions}

We have produced a high-resolution record of atmospheric methane over the past 2,000 years from a sub-tropical and high-altitude ice core. The Dasuopu ice core record indicates an apparent trend of cli- matic warming and methane concentration increase over the past 2,000 years. An abrupt decrease in methane concentration appeared around 1800 AD., which is the coldest period of the Little Ice Age. After the cold period, methane concentrations again dramatically increased. The most important feature of the Dasuopu ice core record is that methane concentrations are higher than in the polar ice core records. This suggests that the low-middle latitudes act as an important methane source, at least during the last 2,000 years.

\section{References \\ Blunier T, Chappellaz, J., Schwander, J., et al. 1993: Atmospheric methane, record from a Greenland ice core over the last 1000 years. Geophys. Res. Lett., 20(20): 2219-2222. \\ Chappellaz, J., Barnola, J.M., Raynaud, D., Korotkev- ich, Y.S. and Lorius, C., 1990: Ice-core record of}

atmospheric methane over the past 160,000 years. Nature, 345: 127-131.

Etheridge, D. M, Steel, L. P., Francey, R. J. and Langenfelds, R. L., 1998: Atmospheric methane between 1000 A.D. and present: evidence of anthropogenic emissions and climatic variability. J. Geophy. Res., 103(D13): 15979-15995.

Thompson, L.G., Yao, T. and Mosley-Thompson, E., 2000: A High-resolution Millennial Record of the south Asian monsoon from Himalayan Ice Cores. Science, 289: 1916-1919.

Xu, B. and Yao, T., 1999: Enclosure of air in the firn at $7100 \mathrm{~m}$ altitude at Dasuopu glacier, J. Glaciology \& Geocryology, 21(4): 380-384.

Yao T., Duan, K., Xu, B. and Wang N., 2002: Temperature and methane changes over the past 1000 years recorded in Dasuopu ice core. Annals of Glaciology, 35: 379-383.

For full references please consult: www.pages-igbp.org/products/newsletters/ref2005_2.html

\title{
Recent Progress and Further Potential: High-resolution Holocene Climate Reconstruction with Coral Reefs in the South China Sea
}

\author{
Ke-Fu YU ${ }^{1}$ AND JiAN-XIN ZHA0 ${ }^{2}$ \\ 'South China Sea Institute of Oceanology, CAS, Guangzhou 510301, China; kyu@earth.uq.edu.au \\ ${ }^{2}$ Advanced Centre for Queensland University Isotope Research Excellence (ACQUIRE), University of Queensland QLD 4072, Australia; \\ j.zhao@uq.edu.au
}

Coral reefs, excellent archives for the environmental history of tropical oceans, are widely distributed in the South China Sea (SCS), which is the biggest enclosed marginal sea of the western Pacific, covering over $16^{\circ}$ in latitude and different climate conditions. The total area of the coral reefs in the SCS is about $7,300 \mathrm{~km}^{2}, \sim 2.5 \%$ of the world's coral reefs (Zhang et al., 2005). Recent research in the SCS focuses mainly on coral-based high-resolution climate reconstruction and coral reef ecological responses using geochemical and U-series geochronological tools, which reveal further potential for understanding of Holocene climate processes and events.

\section{High-resolution Geochemical Proxies for Sea Surface Temperatures (SST) and Salinity in the Mid-late Holocene \\ Combined monthly-resolution skel- etal $\delta^{18} \mathrm{O}, \delta^{13} \mathrm{C}, \mathrm{Sr} / \mathrm{Ca}$ and $\mathrm{Mg} / \mathrm{Ca}$ re- cords for corals from the SCS reveal annual cycles similar to instrumental SST.Theoretically, skeletal $\mathrm{Sr} / \mathrm{Ca}$ is a}

SST proxy, whereas skeletal $\delta^{18} \mathrm{O}$ is a function of both SST and salinity. Our results show that the Sr/Ca-SST relationship is a reliable thermometer, with calculated SST consistent with other independent evidence. By removing the SST-related component in the $\delta^{18} \mathrm{O}$ variation based on calculated $\mathrm{Sr} / \mathrm{Ca}$-SST values, one can obtain the residual $\delta^{18} \mathrm{O}$ that reflects the deviation of the past seawater $\delta^{18} \mathrm{O}$ from the modern value. Thus, the combination of coral $\mathrm{Sr} / \mathrm{Ca}$ and $\delta^{18} \mathrm{O}$ provides a powerful tool for past SST and salinity (related to evaporation and rainfall) reconstruction.

Unlike $\mathrm{Sr} / \mathrm{Ca}, \mathrm{Mg} / \mathrm{Ca}$ is not a reliable proxy for SST despite the fact that its annual cycles are wellcorrelated with instrumental SST. Using the empirical Mg/Ca-SST relationship, we obtained calculated $\mathrm{Mg} / \mathrm{Ca}-\mathrm{SST}$ values for the Holocene corals that are significantly lower than the calculated Sr/Ca-SST values for the same samples, and $\mathrm{Mg} / \mathrm{Ca}$ SST values are also in conflict with coral reef ecology. The unreliability of coral $\mathrm{Mg} / \mathrm{Ca}$ as a thermometer can be interpreted as being due to the presence of a trace amount of microbialites (with $\mathrm{MgO}$ up to $17 \%$, Sr only 100-300 ppm). Preferential loss of Mg during meteoric dissolution of cryptic Mg-calcite-bearing microbialites in the exposed fossil corals (Yu et al., 2005a) will result in reconstructed $\mathrm{Mg} / \mathrm{Ca}$-SSTs being too low.

Using combined $\delta^{18} \mathrm{O}$ and $\mathrm{Sr} / \mathrm{Ca}$ measurements from five Porites corals, mid-late Holocene climate was reconstructed, revealing a general decreasing trend in SST in the SCS from $\sim 6,800$ to 1,500 years ago ( $Y u$ et al., 2005b), despite shorter climatic cycles. Compared with mean $\mathrm{Sr} /$ Ca-SST in the 1990s, 10-year mean $\mathrm{Sr} / \mathrm{Ca}-\mathrm{SST}$ s were $0.9-0.5^{\circ} \mathrm{C}$ higher during 6.8-5.0 kyr BP, dropped to the present level by $\sim 2.5 \mathrm{kyr} B \mathrm{~B}$, and reached a low of $22.6^{\circ} \mathrm{C}\left(2.2^{\circ} \mathrm{C}\right.$ lower $)$ by $\sim 1.5$ kyr BP. Such a decline in SST is accompanied by a similar decrease in the amount of monsoon moisture transported out of SCS, resulting in a general decrease in seawater $\delta^{18} \mathrm{O}$ 